\title{
Car travel demand: spillovers and asymmetric price effects in a spatial setting
}

DOI:

10.1287/trsc.2017.0789

\section{Document Version}

Accepted author manuscript

Link to publication record in Manchester Research Explorer

\section{Citation for published version (APA):}

Thanos, S., Kamargianni, M., \& Schfer, A. (2018). Car travel demand: spillovers and asymmetric price effects in a spatial setting. Transportation Science, 52(3), 621-636. https://doi.org/10.1287/trsc.2017.0789

\section{Published in:}

Transportation Science

\section{Citing this paper}

Please note that where the full-text provided on Manchester Research Explorer is the Author Accepted Manuscript or Proof version this may differ from the final Published version. If citing, it is advised that you check and use the publisher's definitive version.

\section{General rights}

Copyright and moral rights for the publications made accessible in the Research Explorer are retained by the authors and/or other copyright owners and it is a condition of accessing publications that users recognise and abide by the legal requirements associated with these rights.

\section{Takedown policy}

If you believe that this document breaches copyright please refer to the University of Manchester's Takedown Procedures [http://man.ac.uk/04Y6Bo] or contact uml.scholarlycommunications@manchester.ac.uk providing relevant details, so we can investigate your claim.

\section{OPEN ACCESS}




\title{
Car travel demand: spillovers and asymmetric price effects in a spatial setting
}

Sotirios Thanos *

Manchester Urban Institute, University of Manchester

Maria Kamargianni

UCL Energy Institute London, University College London

Andreas Schäfer

UCL Energy Institute London, University College London

\begin{abstract}
A novel analysis framework for the spatial aspects of car travel, measured by vehicle miles travelled (VMT), is introduced in this paper. The specification of a dynamic Spatial Durbin Model (SDM) enables the analysis of VMT spatial spillovers and diffusion between neighboring areas in the short and long-run. The framework is further developed to capture and introduce to a spatial setting potential asymmetry and hysteresis that can reflect reference dependence and habits. A panel dataset is compiled at sub-regional level, based on official car mileage recordings in England and Wales. In addition to the inelastic long-run responses of VMT to fuel price ($0.124)$ and income $(0.116)$ changes, the results illustrate asymmetries and hysteresis in price elasticities with a significant spatial component. The impact magnitude on VMT from a number of factors, such as alternative fuel use, fuel deserts in rural areas, road network and car fleet characteristics, is also estimated. The results are consistent with the car use saturation hypothesis through the positive impact of motorization rate to VMT. The negative effect of public transport infrastructure on car travel is only significant in the spatial models. The paper demonstrates the applicability and importance of spatial econometrics in transport research.
\end{abstract}

This is author accepted manuscript version of the article. This article may be used for non-commercial purposes in accordance with INFORMS Terms and Conditions for Self-Archiving. Please cite as:

Thanos, S., Kamargianni, M., Schäfer, A.W. (2018), Car travel demand: spillovers and asymmetric price effects in a spatial setting. Transportation Science 52(3), 621-636 https://doi.org/10.1287/trsc.2017.0789

\footnotetext{
*Corresponding author, email: sotirios.thanos@manchester.ac.uk

We are grateful to the EPSRC funded RCUK Centre for Energy Epidemiology (CEE): the study of energy demand in a population (EP/K011839/1) for supporting of this study. We also want to thank the three anonymous peer reviewers, the associate editor, and editor in-chief for the very constructive and insightful comments that have led to an improved paper. The content of the paper and any opinions expressed are the sole responsibility of the authors.
} 


\section{Introduction}

Private transport and especially car travel has been a major consumer of petroleum and its continuing prevalence raises questions about the sustainability of current mobility patterns (Ewing et al., 2013; Polydoropoulou et al., 2013; Schäfer and Victor, 2000). A key manifestation of travel demand is vehicle-miles travelled (VMT) by private cars. Despite the extensive literature analyzing VMT with respect to various determinants, there is a lack of explicitly accounting for the spatial aspect of car travel through spatial econometric approaches. Especially the spatial aspects of asymmetries and hysteresis are entirely absent from the literature. These two gaps constitute the focal point of this paper.

A review of the factors affecting VMT shows that income and fuel price effects feature prominently in the literature and are usually inelastic (Hymel et al., 2010; Goodwin et al., 2004). A number of other important aspects of VMT analysis have been discussed in the literature, including congestion (Grimal et al., 2013; Hymel et al., 2010), public transport coverage (Hymel et al., 2010; Sihvola et al., 2012), motorization rate (Schäfer and Victor, 2000), and asymmetries/hysteresis in price and income effects (Dargay, 2007; Dargay and Gately,1997; Hess et al., 2008). Changing consumer preferences, and shifts in lifestyles are some of the additional explanations put forward for the potential car use levelling off (Grimal et al., 2013; Goodwin and Van Dender, 2013; Kamargianni et al., 2014).

More specifically, congestion affects VMT negatively; particularly in high density urban areas where car travel can be substituted by increasingly attractive public transport, cycling, and/or walking (Grimal et al., 2013; Hymel et al., 2010; Kamargianni et al., 2016; Metz, 2010). Car motorization rate also affects VMT negatively, as additional cars in the household are driven less (Schäfer and Victor, 2000). This might not be the complete picture in developed countries, where the spatial variation of motorization rate can also be an indication of car dependency. Dargay (2007) suggests that rising incomes make it easier for households to own cars, and once acquired, cars are not readily disposed of even if the economic conditions worsen, pointing to car dependency. 
The corollary issues of asymmetries and hysteresis, or rather the underlining behavioral causes, have been widely studied in behavioral economics and transport discrete choice modeling literature. Asymmetric responses are caused by consumers weighing losses more than equivalent sized gains, which is attributed to loss aversion and is a specific aspect of reference dependence and the endowment effects (Bao et al., 2014; Hess et al., 2008; Hardie et al., 1993; Tversky and Kahneman et al., 1991). Hysteresis is applicable to transport demand, when there is resistance to change that stems from the tendency of acquiring consumption habits more easily than to abandoning them (Costa and Gerard, 2015; Sharmeen and Timmermans, 2014; Gärling and Axhausen, 2003; Dargay and Gatel, 1997). Imperfect reversibility is defined as the failure of an effect to reverse itself, when its underlying cause is reversed (Dixit, 1989; Dargay and Gatel, 1997).

Studies focusing on loss aversion, reference dependence and endowment effect typically employ disaggregate, cross-sectional data, often derived from stated preference experiments (Masiero and Rose, 2013; Hess et al., 2012; Louviere et al., 2008). There are only few studies using revealed preference data at different levels of aggregation to empirically examine these behavioral issues and their manifestations: asymmetries and hysteresis in this context (Dargay and Gatel, 1997; Dargay 2007; Wadud, 2014). For example, Goodwin (1998), Pendyala et al. (1995), and Dargay (2001) look at successive waves in pseudo-panel setting, relating car ownership changes to periods of income increases and reductions. Their findings present clear indications of asymmetry and hysteresis. The asymmetry and hysteresis concepts can provide causal links between an aggregate level of economic activity, as is the case here, and psychological responses and behavioral factors at the level of individual, such as loss aversion and habit formation.

Travel takes place in space (transport network) and traffic flows are not constrained within a certain area. VMT in a specific area are affected by the VMT and other demographic and transport network characteristics of neighboring areas. There is a gap in the literature regarding the incorporation of spatial and temporal effects in VMT modelling. Advancements in econometric techniques have made possible to capture and quantify such spatio-temporal effects, 
addressing econometric problems that would otherwise result in biased coefficients and imprecise variance estimation (Anselin, 2010; LeSage and Pace, 2009). Even though these techniques have been widely used in other fields (Arbia, 2011), there is only a very limited application of spatial econometrics in transport issues (Sung-Eun and Niemeier 2001; Parent and LeSage, 2010); mostly within an urban economic context (Dubé et al., 2014; Thanos et al., 2015), or employing spatial or spatiotemporal Poisson models to examine transport safety issues (Castro et al., 2012).

To the best of the authors' knowledge, only one study employed spatial econometric methods to analyze VMT. Pirotte and Madre (2011) estimated spatial models employing a panel dataset of the twenty-one French regions for 1973-1999. However, their model specification allows only the derivation of short-run elasticities with respect to VMT, and is in detail discussed in section 2.1.

Against this background, the paper provides a flexible methodological framework that captures the spatial and temporal aspects of car travel, by enabling the robust application of spatial panel models to car travel demand. This framework is further developed to capture asymmetries and hystereses in a spatial setting. The existence and type of spatial interactions and the presence of asymmetries/hystereses are then tested on revealed preference data. The data, compiled from a number of sources, is based on officially recorded car mileage information at sub-regional level in England and Wales. Drawing on the literature, the modelling approach includes information on fuel prices, income levels, alternative fuel use, road network and car fleet characteristics, petrol stations, motorization rate, and public transport infrastructure.

We continue with Section 2, which introduces the methodological framework for spatial models applied to VMT and its extension for capturing asymmetries and hysteresis. Section 3 describes the data sources, the variable derivation and data characteristics. Section 4 presents and discusses the modelling results. The conclusions follow in Section 5. 


\section{Methodology}

This section addresses two methodological challenges for the estimation of a spatial model using panel data: first, the introduction of spatial econometrics to a sub-regional VMT model applied to panel data; second, the development of the spatial panel model to account for the behavioral aspects of reactions to fuel price changes that translate to asymmetries and hystereses.

\section{1. $\quad$ Spatial panel models developed for VMT}

Given that car travel varies across space and changes over time, the VMT per car, $y$, in a certain in area $i(1 \ldots i \ldots n)$, at time $t(1 \ldots \tau)$ depends on the VMT effect $(\lambda)$ from the previous period, and the impact $(\beta)$ of $K$ independent variables $(x)$, such as fuel price, income, public transport infrastructure, road network and car fleet characteristics, motorization rate. This is the base model shown in Eq. 1, where $\mu$ is the heterogeneity component of either fixed of random effects and $\varepsilon$ is an error term.

$y_{i t}=\beta_{0}+\lambda y_{i t-1}+\sum_{k=1}^{K} x_{i t k} \beta_{k}+\mu_{i}+\varepsilon_{i t}$

The vast majority of the literature adopts a log-linear specification (e.g. Schäfer and Victor, 2000; Pirotte and Madre, 2011; Dargay and Gately, 1997) and the constant elasticity model specification simplifies the estimation process $^{1}$; hence, for brevity: $y \stackrel{\text { def }}{=} \operatorname{Ln}(y)$ and $x \stackrel{\text { def }}{=} \operatorname{Ln}(x)$. Equation 1 is estimated through least squares (LS) here and is based on the assumption of no spatial interrelationships between the different areas.

Our hypothesis is that car travel in a specific area can be affected by the car travel, road network, and socioeconomic characteristics of other areas; therefore these interactions should be tested. Advances in spatial econometrics allow the estimation and testing of three different types of interactions between units/areas/observations ${ }^{2}$ (LeSage and Pace, 2009). These are: 1) the

\footnotetext{
${ }^{1}$ The Box-Cox specification or similar specifications that estimate rather than assume the functional form are not readily implemented in the presence of spatial dependence (Kim et al., 2003). Furthermore, Goodwin et al. (2004) found no strong consistent pattern of effect of functional form.

${ }^{2}$ The existence of any of these interactions would render the OLS estimation biased and/or inefficient.
} 
endogenous spatial interrelationships of the dependent variable at time $t$ and/or endogenous spatiotemporal effects from the past at $t-1$; 2) the exogenous spatial interaction in the explanatory variables; and 3) spatial interaction in the residuals (Elhorst, 2014).

In the VMT context, the first type of interaction signifies that the VMT of neighboring areas are spatially interrelated, accounting for the significant proportion of trips usually shared between neighboring areas. This type of model is analogous to a temporal autoregressive specification, differing in that the effect is not unidirectional from past to present, but bi-directional between the neighboring areas. There can be also a spatiotemporal effect from VMT of neighboring area $j$ at $t-1$, affecting the VMT of area $i$ in the subsequent time period $t$. The second type of interaction means that attributes of an area, such as fuel prices, or road network characteristics, can affect the VMT of a neighboring area. The third type of interaction signifies that VMT is affected by unobserved spatial characteristics of neighboring areas, for example urban form, resulting into the model residuals containing spatial patterns instead of white noise.

Spatial weights a priori specify the spatial relations between observations or areas in the form of a matrix $\mathbf{W}$ of dimensions $(n \tau \times n \tau)$, as the $n$ cross-sections are stacked over $\tau$ times. The matrix contains the spatial link between observations $i$ and $j, w_{i j}$, representing the strength of their spatial connection that is typically a function of distance shown in Equation 2.

$\mathrm{w}_{i j}=\left\{\begin{array}{l}f\left(\mathrm{~d}_{i j}\right) \forall i \neq j \\ 0 \quad \forall i=j\end{array} i, j \in(1 \ldots n)\right.$

Given data availability constraints, we specify the simplest and only form of spatial interaction we can be confident in at this stage. That is the contiguous weight matrix shown in Equation 3, where only areas that share a boundary (bnd) are taken to have a spatial relationship. Row normalization of $\mathbf{W}$ is applied to make the corresponding coefficients readily interpretable.

$\mathrm{w}_{i j}= \begin{cases}1 & \forall \operatorname{bnd}(i) \cap \operatorname{bnd}(j) \neq \varnothing \\ 0 & \forall \operatorname{bnd}(i) \cap \operatorname{bnd}(j)=\varnothing\end{cases}$ 
Equation 3 assumes that VMT and other characteristics from contiguous area $j$ impact the VMT of a specific area $i$ and vice versa. This is reasonable for commuting and short distance trips, given the data constraints outlined in section 3 and especially the lack of information on long distance trips and their prevalence.

Pirotte and Madre (2011) choose as their preferred specification a row normalized matrix of inverse distances between regional capitals. This would denote strong and un-testable assumptions about car travel interrelations between distant regions. However, a key shortcoming of row normalizing an inverse distance matrix, as Elhorst (2014) stresses, is that its economic interpretation in terms of distance decay is no longer valid. The main consequence is that remote and central regions end up having similar impact, independent of their relative location. Due to data constraints, Pirotte and Madre (2011) also calculate VMT using information on fuel sales, changes in fuel efficiency, and share of fuel use by light vehicles. The fuel sales are available at regional level whereas the other two pieces of information are available only at a national level.

Illustrating the different spatial models and their significance in this context, we start from third type of spatial interaction assumption of unobserved processes, not uniformly distributed in space, affecting the VMT and the residuals in Equation 1. The spatial error model (SEM) in equations 4 and 5 captures this spatial structure. Equation 4 shows a vector $y_{t}$ of the dependent variable, in $n$ areas $(1 \ldots i \ldots n)$, depending on a matrix $\boldsymbol{X}_{t}$ of explanatory variables including the constant of dimensions $[n \times(K+1)]$.

$\boldsymbol{y}_{t}=\lambda \boldsymbol{y}_{t-1}+\boldsymbol{X}_{t} \boldsymbol{\beta}+\boldsymbol{u}_{t}$

$\boldsymbol{u}_{t}=\rho \boldsymbol{W} \boldsymbol{u}_{t}+\boldsymbol{\varepsilon}_{t}$

where $\boldsymbol{\beta}[(K+1) \times 1]$ is the vector of parameters, $\boldsymbol{u}_{t}$ and $\boldsymbol{\varepsilon}_{t}$ are vectors of disturbance terms. $\boldsymbol{u}_{t}$ can also be expressed as in equation 6 :

$\boldsymbol{u}_{t}=\boldsymbol{\varepsilon}_{t}(\boldsymbol{I}-\rho \boldsymbol{W})^{-1}$ 
where $\boldsymbol{I}$ is the identity matrix, and $\rho$ is the spatial autocorrelation coefficient. Substituting 6 into 4, solving for $\boldsymbol{\varepsilon}$ and rearranging we get Equation 7, which constrains the spatially lagged $\boldsymbol{y}$ and the spatially lagged $\boldsymbol{X}$ not to vary independently (Burridge, 1981). Another constraint is that spatiotemporally lagged $\boldsymbol{y}$ don't vary independently to the spatial and temporal elements either.

$\boldsymbol{y}_{t}=\lambda \boldsymbol{y}_{t-1}-\rho \lambda \boldsymbol{W} \boldsymbol{y}_{t-1}+\rho \boldsymbol{W} \boldsymbol{y}_{t}+\boldsymbol{X}_{t} \boldsymbol{\beta}+\boldsymbol{W} \boldsymbol{X}_{t}(-\rho \boldsymbol{\beta})+\boldsymbol{\varepsilon}_{t}$

To obtain a more flexible specification that allows to test a number of different constraints and restrictions that assume different model forms ${ }^{3}$, we substitute $-\rho \boldsymbol{\beta}$ with $\boldsymbol{\theta}$, and $-\rho \lambda$ with $\gamma$, allowing $\boldsymbol{\theta}$ and $\gamma$ to vary independently of $\rho, \lambda$, and $\boldsymbol{\beta}$, as shown in Equation 8 below:

$\boldsymbol{y}_{t}=\lambda \boldsymbol{y}_{t-1}+\gamma \boldsymbol{W} \boldsymbol{y}_{t-1}+\rho \boldsymbol{W} \boldsymbol{y}_{t}+\boldsymbol{X}_{t} \boldsymbol{\beta}+\boldsymbol{W} \boldsymbol{X}_{t} \boldsymbol{\theta}+\boldsymbol{\varepsilon}_{t}$

Bearing in mind Gibbons and Overman (2012) admonition of mechanically applying spatial econometrics and selecting models solely based on goodness of fit, we provide a brief theoretical justification for the inclusion of different elements of equation 8 in the final model. The dynamic temporal autoregressive element of VMT $\left(\lambda \boldsymbol{y}_{t-1}\right)$ is justifiable, especially since omitting a relevant time lag term can result in significant biases, while including an irrelevant time lag term causes little loss of efficiency in spatial models, as shown by Tao and Yu (2012). VMT of neighboring areas can be spatially interrelated $\left(\rho \boldsymbol{W} \boldsymbol{y}_{t}\right)$, accounting for the significant proportion of trips usually shared between neighboring areas.

While the approach of Debarsy et al. (2012) of including $\gamma \boldsymbol{W} \boldsymbol{y}_{t-1}$ may be appropriate for examining cigarette consumption, we content that it might not be as appropriate for car travel demand. As mentioned above, car users do react to current VMT and resulting road conditions of neighboring areas $\left(\rho \boldsymbol{W} \boldsymbol{y}_{t}\right)$. Car users are also affected by the VMT in previous periods $\left(\lambda \boldsymbol{y}_{t-1}\right)$ in their own area, which is in turn influenced by the contemporaneous VMT of neighboring areas. However, $\gamma \boldsymbol{W} \boldsymbol{y}_{t-1}$ signifies that there is an additional and separate spatiotemporal effect from the past VMT in contiguous areas. Since we cannot hypothesize any valid underlining

\footnotetext{
${ }^{3}$ Model form is used interchangeably here to "data generating process" (DGP).
} 
reason for such a spatiotemporal $\mathrm{lag}^{4}$, we see little economic justification for such an effect in this transport demand context. Nevertheless, we do proceed to test for $\gamma=0$ in section 4.2.

The VMT interrelationship effect between area $i$ and area $j\left(1^{\text {st }}\right.$ type interaction) may well be different to the influence of the characteristics $(\boldsymbol{X})$ of area $j$ to the VMT of area $i$ ( $2^{\text {nd }}$ type interaction). This constraint $\left(\boldsymbol{W} \boldsymbol{X}_{t}(-\rho \boldsymbol{\beta})\right)$ in equation 7 seems unrealistic in this context, as there is asymmetrical divergence in travel patterns, infrastructure, public transport availability, and land use characteristics between different areas. If $\boldsymbol{\theta}=-\rho \boldsymbol{\beta}$, we get a SEM (Equations 4-5 or 7). If $\boldsymbol{\theta}=0$, the resulting model is a spatial autoregressive (SAR) specification that can include temporal and spatiotemporal lags. Equation 9 provides the dynamic SAR specification (only $1^{\text {st }}$ type interaction) without a spatiotemporal lag $(\gamma=0)$.

$\boldsymbol{y}_{t}=\lambda \boldsymbol{y}_{t-1}+\rho \boldsymbol{W} \boldsymbol{y}_{t}+\boldsymbol{X}_{t} \boldsymbol{\beta}+\boldsymbol{\varepsilon}_{t}$

If both $\boldsymbol{\theta}+\rho \boldsymbol{\beta} \neq 0$ and $\boldsymbol{\theta} \neq 0$ then the dynamic Spatial Durbin Model (SDM) is employed, containing both the first and second types of spatial interactions in Equation 8. Section 4.2 provides the test results for all the constraints discussed here: $\boldsymbol{\theta}=-\rho \boldsymbol{\beta}, \boldsymbol{\theta}=0$, and $\gamma=0$.

Even though certain independent variables, such as public transport networks, fuel price, motorization rate, and congestion are indeed expected to have significant spatial effects on neighboring VMT, this may not be the case with all independent variables. This is taken into account in equations 10 and 11 that are estimated in section 4.2:

$$
y_{i t}=\beta_{0}+\lambda y_{i t-1}+\gamma \sum_{j=1}^{n} w_{i j} y_{j t-1}+\rho \sum_{j=1}^{n} w_{i j} y_{j t}+\sum_{k=1}^{K} x_{i t k} \beta_{k}+\sum_{k=1}^{k-m} \sum_{j=1}^{n} w_{i j} x_{i t(k-\theta)} \theta_{k-m}+\mu_{i}+\varepsilon_{i t}
$$

where $m$ is the number of independent variables without any spatial effect. If $\gamma=0$, then we get:

\footnotetext{
${ }^{4}$ If $\boldsymbol{W}$ is time invariant, there may be an issue of double counting when we include $\gamma \boldsymbol{W} \boldsymbol{y}_{t-1}$, as $\boldsymbol{y}_{t}$ is affected by $\boldsymbol{y}_{t-1}$ and $\boldsymbol{W} \boldsymbol{y}_{t}$, and $\boldsymbol{y}_{t-1}$ is in turn affected by $\boldsymbol{W} \boldsymbol{y}_{t-1}$. This is an issue that may require further research. There is spatial and temporal variation in our data, but no spatiotemporal variation. If $\mathbf{W}$ was time variant, then $\gamma \boldsymbol{W} \boldsymbol{y}_{t-1}$ would be essential.
} 


$$
y_{i t}=\beta_{0}+\lambda y_{i t-1}+\rho \sum_{j=1}^{n} w_{i j} y_{j t}+\sum_{k=1}^{K} x_{i t k} \beta_{k}+\sum_{k=1}^{k-m} \sum_{j=1}^{n} w_{i j} x_{i t k} \theta_{k-m}+\mu_{i}+\varepsilon_{i t}
$$

Two additional reasons reinforce the selection of SDM as the preferred specification in this context. First, it is less sensitive to omitted variable bias caused by un-captured spatial information $^{5}$. Second, SDM minimizes non-identification ${ }^{6}$ issues that are prevalent in other spatial econometric models. Besides having little theoretical basis in the VMT context, a general spatial model (including all three types of spatial interactions) would forgo the SDM advantages, severely compromising identification and tractable estimation (Gibbons and Overman, 2012; Le Gallo, 2002; LeSage, 2014).

We adopt the Quasi-Maximum Likelihood (QML) estimator by Yu et al. (2008) that can handle the dynamic fixed effects SDM in Equations 10 and 11 (see Table 3 for tests of fixed versus random effects). Elhorst (2010) found that the Yu et al. (2008) QML estimator outperforms the other estimators in terms of bias and root mean squared error when $\tau=5$, which is the case for our data.

Only in the case of SEM are the coefficients $(\boldsymbol{\beta})$ directly interpretable as the impact of explanatory variable changes to VMT. LeSage and Pace (2009) demonstrate that the partial

\footnotetext{
5 Lacombe and LeSage (2013) confirm that SDM specification works well, producing unbiased parameters, in all circumstances of correlation between omitted and included variables. Conversely, the SEM specification works well only in the extreme case of zero correlation between omitted and included variables. Furthermore, significant t-statistics for the indirect effects identify these omitted variable problems. The identification and accounting for omitted variable bias provides flexibility and contributes to the alleviation of the two key concerns in spatial econometrics: the a priori assumption that model form and $\boldsymbol{W}$ are complete and correct maps of spatial interactions.

${ }^{6}$ Gibbons and Overman (2012) indicate a potential identification problem of not recovering the unique unknown parameters from reduced model forms that contain a spatial autoregressive term. However, Bramoullé et al. (2009), examining the application of the SDM in the context of social network interactions, deliver a fundamental insight by providing the necessary and sufficient conditions for the identification of parameters $\boldsymbol{\beta}, \rho, \boldsymbol{\theta}$. Identification is achieved provided that $\boldsymbol{\theta}+\rho \boldsymbol{\beta} \neq 0$, for all $\rho$ such that $(\mathbf{I}-\rho \boldsymbol{W})^{-1}$ exists. Even though identification may fail for some particular structures of $\boldsymbol{W}$, these are not relevant to the VMT context of spatial interactions.
} 
derivative, the only valid basis for testing hypotheses and interpreting the impact of variable changes (marginal effects and elasticities), is not equal to $\boldsymbol{\beta}$ in the case of SDM and SAR. This is due to the spatial autoregressive effect ( $1^{\text {st }}$ type interaction) that creates a feedback loop for dependent variable changes passing through the dependent and explanatory variables of adjacent areas. Therefore, it is possible to distinguish between and estimate direct and indirect (spillover) spatial effects that are elasticities in our specification. The total short run elasticities are the combination of direct and indirect elasticities given for dynamic SDM in Equation 12 (Vega and Elhorst, 2015).

$\boldsymbol{\Psi}_{\boldsymbol{S}} \stackrel{\text { def }}{=}\left[\frac{\partial \mathrm{E}(\boldsymbol{y})}{\partial x_{1 k}} \cdots \frac{\partial \mathrm{E}(\boldsymbol{y})}{\partial x_{n k}}\right]=(\mathbf{I}-\rho \boldsymbol{W})^{-1}\left[\begin{array}{cccc}\beta_{\mathrm{k}} & \mathrm{w}_{12} \theta_{k} & \cdots & \mathrm{w}_{1 n} \theta_{k} \\ \mathrm{w}_{21} \theta_{k} & \beta_{\mathrm{k}} & \cdots & \mathrm{w}_{2 n} \theta_{k} \\ \vdots & \vdots & \ddots & \vdots \\ \mathrm{w}_{\mathrm{n} 1} \theta_{k} & \mathrm{w}_{\mathrm{n} 2} \theta_{k} & \cdots & \beta_{k}\end{array}\right]=(\mathbf{I}-\rho \boldsymbol{W})^{-1}\left[\mathbf{I} \boldsymbol{\beta}_{k}+\boldsymbol{W} \boldsymbol{\theta}_{k}\right]$

Equation 13 provides the equivalent long-run elasticity formula (Elhorst, 2014).

$\boldsymbol{\Psi}_{L} \stackrel{\text { def }}{=}[(1-\lambda) \mathbf{I}-\rho \boldsymbol{W}]^{-1}\left[\mathbf{I} \boldsymbol{\beta}_{k}+\boldsymbol{W} \boldsymbol{\theta}_{k}\right]$

The diagonal elements of the matrix $\boldsymbol{\Psi}_{\boldsymbol{S}}$ represent the direct effects and the off-diagonal elements, the indirect or spill-over effects (Vega and Elhorst, 2015). The direct effects denote the influence of an independent variable change in a particular area on that area's VMT, incorporating feedback effects of the adjacent areas and to the area in which the adjustment process was initiated. The indirect impact represents the effect of an independent variable change in a particular area on the VMT of all the contiguous areas. The explanation is equivalent for the long run elasticity matrix $\boldsymbol{\Psi}_{L}$ that also includes the temporal dynamic component $(1-\lambda)^{-1}$.

The total effects of SAR are different to SDM, as $\boldsymbol{\theta}=0$, and $\boldsymbol{\Psi}_{\boldsymbol{S}}$ becomes $(\mathbf{I}-\rho \boldsymbol{W})^{-1}\left[\mathbf{I} \boldsymbol{\beta}_{k}\right]$. Hence, the marked difference between SAR and SDM is that the ratio of the indirect and direct effects is the same for all independent variables in SAR. There is no theoretical justification for such a restriction and this is one of the reasons SDM is in principle preferred to SAR in this context. 


\subsection{Decomposing the price, asymmetry and hysteresis in a spatial setting}

As discussed in section 1, asymmetric responses are potentially caused by loss aversion, reference dependence and the endowment effect, hysteresis reflects established habits and the ensuing inertia. The next step is to operationalize the process and introduce this specification to spatial panel models for the first time in the literature. This approach provides a way to examine the link between behavioral aspects and their spatial dimension in this context.

The variable decomposition to capture asymmetries was first proposed by Wolffram (1971) and later improved to detect hysteresis effects (Dargay and Gately, 1997) that has subsequently become the standard in the transport and energy "asymmetry-hysteresis" literature (Wadud, 2014). However, the typical time-series formulae in the literature (e.g. Dargay and Gately, 1997; Wadud, 2014) is not precise enough to allow clear operationalization of the process. Hence, we provide precise formulae for the panel format below. The decomposition is then further advanced to introduce asymmetries and hysteresis in the spatial dimension.

The variable $x_{i t g}[g \in(1 \ldots K)]$, in this case the fuel price, is decomposed into three components given in Equations 14-16 (we drop subscript $g$ for brevity).

$x_{i t}^{m}=x_{i 1}+ \begin{cases}\sum_{t=2}^{\tau}\left(\Delta x_{i t}\right), & \forall \Delta x_{i t}=\left(x_{i t}-x_{i t-1}\right)>0 \\ 0, & \forall \Delta x_{i t} \leq 0\end{cases}$

$x_{i t}^{m}$ refers to only positive cumulative increases added on the initial value of the variable at $t=1$. This captures the perceived general level of prices.

$x_{i t}^{c}=\sum_{t=1}^{\tau}\left(\Delta x_{i t}\right), \forall \Delta x_{i t}<0$

$x_{i t}^{c}$ refers to the cumulative series of only the reductions in the value of the variable, this is monotonically decreasing, and always negative. This captures consumer reactions to price decreases.

$$
x_{i t}^{r}=\left\{\begin{aligned}
0+\sum_{t=2}^{\tau}\left(\Delta x_{i t}\right), & \forall \Delta x_{i t} \geq 0 \wedge \Delta x_{i t}>\left(\Delta x_{i t-h}<0\right) \\
0, & \forall \Delta x_{i t}<0
\end{aligned}\right.
$$


Where $h$ is a positive integer $\left(h \in \mathbb{N}^{*}\right)$ and $t-h>0 . \quad x_{i t}^{r}$ is a monotonically increasing cumulative recovery in the variable value preceded by a reduction, immediately or before $h-1$ periods of no change. This component captures the consumer reaction to price recovery after decreases.

As the word decomposition denotes: $x_{i t}=x_{i t}^{m}+x_{i t}^{r}+x_{i t}^{c}$. Imperfect price reversibility holds when the parameters of $x_{i t}^{m}, x_{i t}^{r}, x_{i t}^{c}$ are unequal. Asymmetry holds when reactions to price reductions, $x_{i t}^{c}$, and price recovery, $x_{i t}^{r}$, are statistically different, indicating potential loss aversion and reference dependence. Hysteresis holds when the coefficients of $x_{i t}^{m}$ and $x_{i t}^{r}$ are different, denoting that responses to price increases depend on price history, and on whether the current price is above or below a previous maximum (Wadud, 2014).

This decomposition is extended to the spatial dimension by introducing the component(s) of the decomposed price into $\boldsymbol{W} \boldsymbol{X} \boldsymbol{\theta}$. This provides the spatial aspects of the three price components: $w_{i j} x_{j t}^{m} \theta^{m}, w_{i j} x_{j t}^{r} \theta^{r}, w_{i j} x_{j t}^{c} \theta^{c}$.

An example of a distinct spatial aspect of a price effect would be big rises in the overall price levels, $x_{i t}^{m} \beta^{m}$, having a direct negative impact to VMT, but also having a positive indirect effect $w_{i j} x_{j t}^{m} \theta^{m}$ due to the extra mileage in search of petrol stations with lower prices. A number of spatial aspects of potential imperfect reversibility can be tested through statistically significant differences between $w_{i j} x_{j t}^{m} \theta^{m}, w_{i j} x_{j t}^{r} \theta^{r}, w_{i j} x_{j t}^{c} \theta^{c}, x_{i t}^{m} \beta^{m}, x_{i t}^{r} \beta^{r}$, and $x_{i t}^{c} \beta^{c}$.

This section, in addition to theoretical justification for employing spatial econometrics in a car travel demand context, also provides a robust model specification that has the following advantages compared to "a-spatial" and/or standard spatial models: First, the dynamic SDM is a flexible specification that allows the testing and removal of restrictions producing SAR or SEM. Second, SDM minimizes potential biases and issues of non-identification that are prevalent in spatial econometric models. Third, the dynamic SDM is one of very few feasible spatial models 
(Elhorst, 2014) that can allow us to account for the spatial aspects of behavioral effects, by analyzing asymmetry and hysteresis in a spatial setting, in both the short and long-run.

\section{Data and Model Specification}

\subsection{Data}

As the literature suggests, information on socioeconomic, road network and car fleet characteristics, fuel prices, and competition between modes of travel is needed to robustly estimate car travel demand models. The diversity of the required information necessitates in this context the combination of data from a number of sources and the use of proxies in cases of unavailable information. Compiled from a range of observed sub-regional data, the dataset employed here includes third party recorded car mileage, instead of survey self-reporting or of estimation from a number of spatially un-matching aggregate information. The car mileage data are recorded during the annual test of vehicle roadworthiness, MOT (DVSA, 2013), for 20052010. These are merged into a panel dataset of 105 areas in England and Wales with spatially disaggregate data on petrol prices and total fuel volume (Experian Catalist, 2014), disposable income (ONS, 2015), public transport availability (DfT, 2014), road network (Ordinance Survey, 2014), population and area census data (ONS, 2011).

The MOT data includes the vehicle characteristics, engine size, make-model, age, fuel and odometer readings from 2005-2013 (DVSA, 2013) of over 23 million tests per year in England and Wales ${ }^{7}$. The analysis here focuses specifically to the vehicle category that includes only cars and vans. Vehicles under other driving license categories, such as taxis, ambulances, freight vehicles and motorbikes are not included, as their use is determined by markedly different factors than private cars. One limitation of MOT is that it is undertaken by cars after they complete 3 years of use. Hence, any "new car" effect on mileage cannot be captured by this dataset. The MOT data include a vehicle identifier, which can be used to calculate the miles travelled by each car between tests by the respective odometer readings. However, there is a

\footnotetext{
${ }^{7}$ Except the first year of data availability, 2005, when only 5.5 million tests were recorded. DfT did not provide any clarification on the issue.
} 
critical error in the continuity of the vehicle identifier in 2011. The same vehicle can be identified in 2005-2010 and 2011-2013, but cannot be matched between the two periods ${ }^{8}$. Therefore, we use the data of the longest time period, 2005-10.

The only spatial identifier available in MOT data is the postcode area ${ }^{9}$ that translates to 105 areas in England and Wales. These areas are comparable and just over the size of NUTS3 ${ }^{10}$ areas for England and Wales. However, two areas (the WC and EC postcodes) in the center of London were dropped due to missing data in 2005, reducing the cross-sections to 103 . Furthermore, WC and EC have at least an order of magnitude less land area, respectively 357 and 413 hectares, than any other postcode area (e.g. the next postcode area size is 5482 hectares) in the UK at the same level of spatial disaggregation. Given the uniqueness and peculiarity of the center of London with respect to car use, these areas are beyond the topic and data availability of this paper.

As MOT tests may not take place exactly a year apart for each car, DfT (2013) guidelines were followed in weighting the observation according to the days elapsed between tests. Equation 17 shows the calculation of VMT per car/area/year, $y_{i t}$ from the MOT data.

$y_{i t}=\left(\sum_{c=1}^{C}\left\{\left(O_{c t+1}-O_{c t}\right) \times\left[365 /\left(d_{c t+1}-d_{c t}\right)\right]\right\}\right) / C_{i t}, \forall\left(d_{c t+1}-d_{c t}\right)>90$

where $O_{c t}$ is the odometer reading of car $c$ at year $t$ and $d_{c t}$ is the date of MOT of car $c$ in year $t$, and $C_{i t}$ is the number of cars in area $i$ and year $t$. Prior to deriving VMT per car/area/year, we followed DfT (2013) recommendations to drop negative, extreme values of VMT over 100,000

\footnotetext{
${ }^{8}$ This problem was reported to DfT and acknowledged on 02/05/2014, but to our knowledge there has not been a correction to date.

${ }^{9}$ The first two digits of the full postcode.

${ }^{10}$ Nomenclature of Units for Territorial Statistics (NUTS) is a geocode standard for referencing the subdivisions of countries for statistical purposes across the European Union.
} 
miles per year and observations of cars that underwent two MOTs within 90 days ${ }^{11}$. As a result, the VMT per car per area was calculated from 16,127,410 observations of individual car VMTs in 2007, reaching 18,342,062 observations in 2010.

The second source of information is the Experian Catalist (2014) petrol station database, which is routinely used in UK government reports (Defra, 2012 and Office of Fair Trading, 2013). This is the only dataset in the UK that exhibits the required spatial disaggregation and temporal coverage appropriate for this study, containing information on petrol/diesel prices, petrol stations, and fuel volume sold. Fuel cards provide price data whereas regular petrol stations surveys provide the remaining information. Experian Catalist (2014) states that all petrol stations are covered in the survey, but the price data comes from $83 \%$ of fuel sites, which account for approximately $98 \%$ of UK fuel volume. This data was used to derive the petrol prices, total mixed fuel volume, and petrol station number per area for each year between 2005 and 2010. It is also combined with MOT data to create an interaction variable between fuel volume consumed and the engine size per area/car/year.

The disposable income data (ONS, 2015) is, to our knowledge, the only available spatially disaggregate household annual income estimate in the UK at the required level of spatial disaggregation and time coverage. The disposable income data is actually at a NUTS3 area level, thus ONS (2014) look up tables were employed to match the 111 NUTS3 areas to the 105

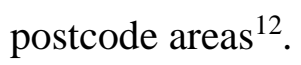

The National Public Transport Access Nodes (NaPTAN) database (DfT, 2014) is a nationwide system for uniquely identifying all the points of access to public transport in the UK. Different versions of the data were employed, covering a period 2003-2014, to capture the changes in

\footnotetext{
${ }^{11}$ MOTs this close together signify car problems and a repeated test. However, there is no obvious nonrandom component to raise concerns about selection bias. If these were not dropped, Equation 17 would have assigned excessive weight to observations of very low or high mileage by extrapolating the one month mileage to a whole year, skewing the results.

${ }^{12}$ As not all areas matched perfectly, the NUTS3 disposable income of 111 areas was expanded to the 181,408 Census outputs areas (COAs). The average income of output areas in postcode area $i$ was computed as follows: $\overline{\text { income }_{l}}=\frac{\sum_{k=1}^{Z} i n c o m e_{k}}{z}$, where $z$ is the number of COAs in area $i$.
} 
public transport infrastructure over the study period. The MasterMap Integrated Transport Network Layer (ITNL) (Ordnance Survey, 2013) was introduced to GIS software in conjunction with NaPTAN to pinpoint and derive the number of public transport infrastructure and road network lane miles per postcode area. Unfortunately, no information on congestion was available at this level of spatial aggregation. Therefore, an interaction variable of total fuel consumed per lane mile is employed as a proxy for lower speed traffic.

To include potential effects of alternative fuels on car travel demand, a proxy is created for using the alternative fuel (or its equivalent of standard fuel volume) consumption $V A_{i t}$ in area $i$ and time $t$ as shown in equation 18.

$p_{i t}=\frac{V A_{i t}}{V A_{i t}+V F_{i t}} \Leftrightarrow V A_{i t}=\frac{p_{i t}}{\left(1-p_{i t}\right)} V F_{i t}$

where $V F_{i t}$ is the standard (petrol and diesel) fuel volume available in Experian Catalist (2014) data. $p_{i t}$ is the percentage of alternative fuel to total fuel use, which is not available. Therefore, it is approximated by the percentage of alternative fuel car mileage to the total car VMT from the MOT data. Recognizing the limitations, $V A_{i t}$ is the only proxy option for alternative fuel use, given the information availability.

The Census data for England and Wales (ONS, 2011) contain a wealth of information on land area, population, dwelling and socioeconomic characteristics. However, census provides data only for one year (2011) and as such it was used only for deriving area size and population characteristics, as it cannot be further employed in the fixed effects panel models, due to the strictly cross-sectional nature of the data. While we recognize that the Modifiable Areal Unit Problem (MAUP) may result to distortions from the choice of a specific spatial aggregation level (Briant et al., 2010), the lack of any other spatial information provides no such choice here. The resulting panel data captures the spatial and temporal aspects of car use, which are both essential for modelling, as seen in the literature and the methodology sections. 


\subsection{Data characteristics}

This subsection presents an overview of key data characteristics, highlighting the variation over time and across areas, as illustrated in Figure 1. Income, car ownership and engine size show substantial spatial variation, while petrol prices seem bunched together across space, bearing in mind though that these prices are area annual means and mainly consist of taxes that don't vary across space and time. Regarding the temporal dimension, it is a quite evident that the petrol price variation consists of increases, reductions and recoveries, which seems to qualify the decomposition in section 2.2 even in such a short time-series. Unfortunately, the same is not true for income that exhibits small temporal variations and a slight increase across all areas over time.
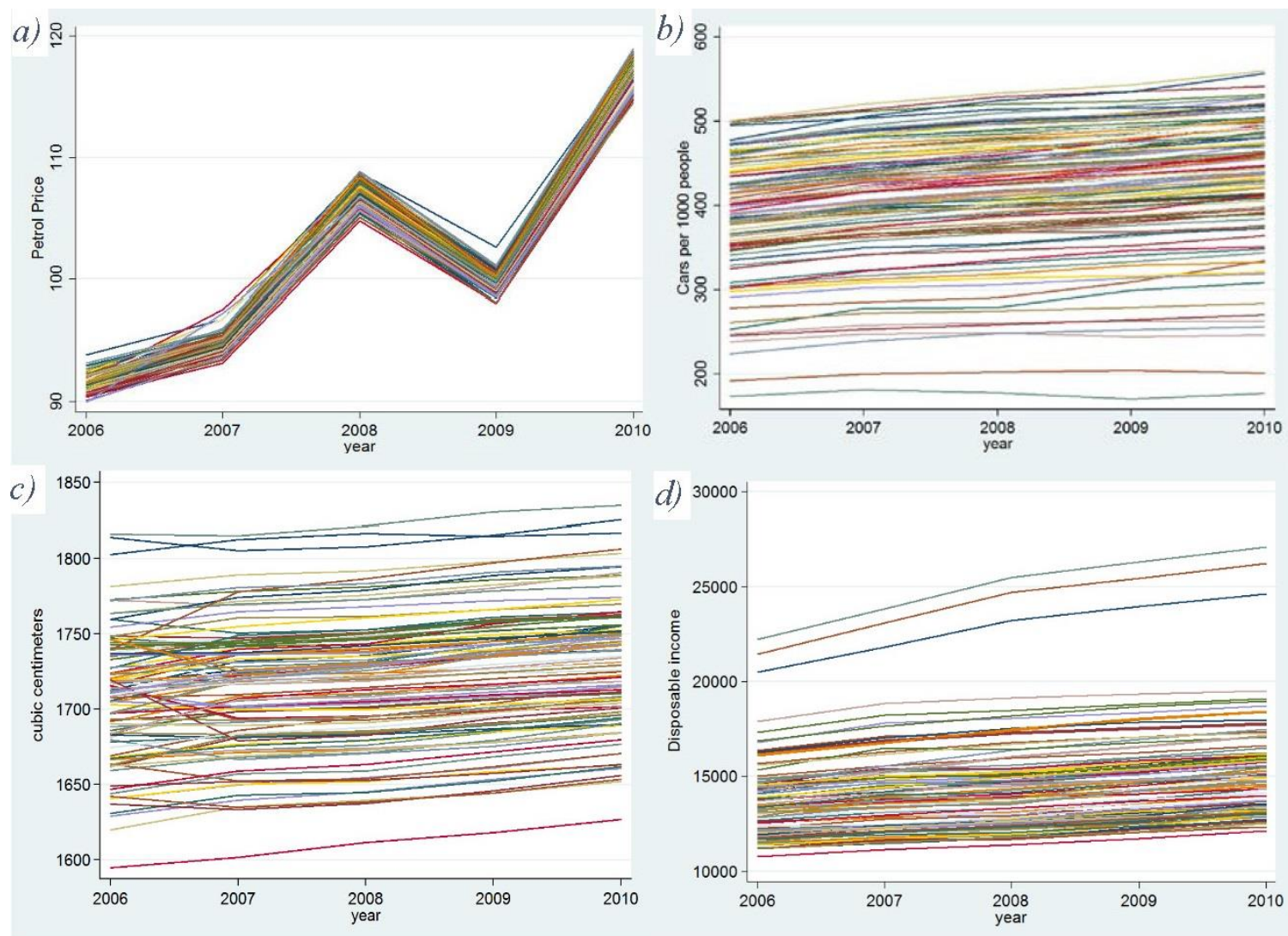

Figure 1: a) Petrol prices (pence), b) Cars per 1000 people, c) Disposable income per household $(£), d)$ Average engine size (cubic centimeters) across areas 
The VMTs per car/area from equation 17 are shown in Figure 2, where one can indeed see substantial spatial variation, reaching 3,500 miles per car per area. Contrary to income, car ownership, and engine size, we see a shallow negative trend in the VMT across time. It would be interesting to gauge whether this negative trend is still significant after the other spatial and temporal factors that affect VMT have been accounted for. Table 1 provides the definition, the sources, and the descriptive statistics of the variables used in the models.

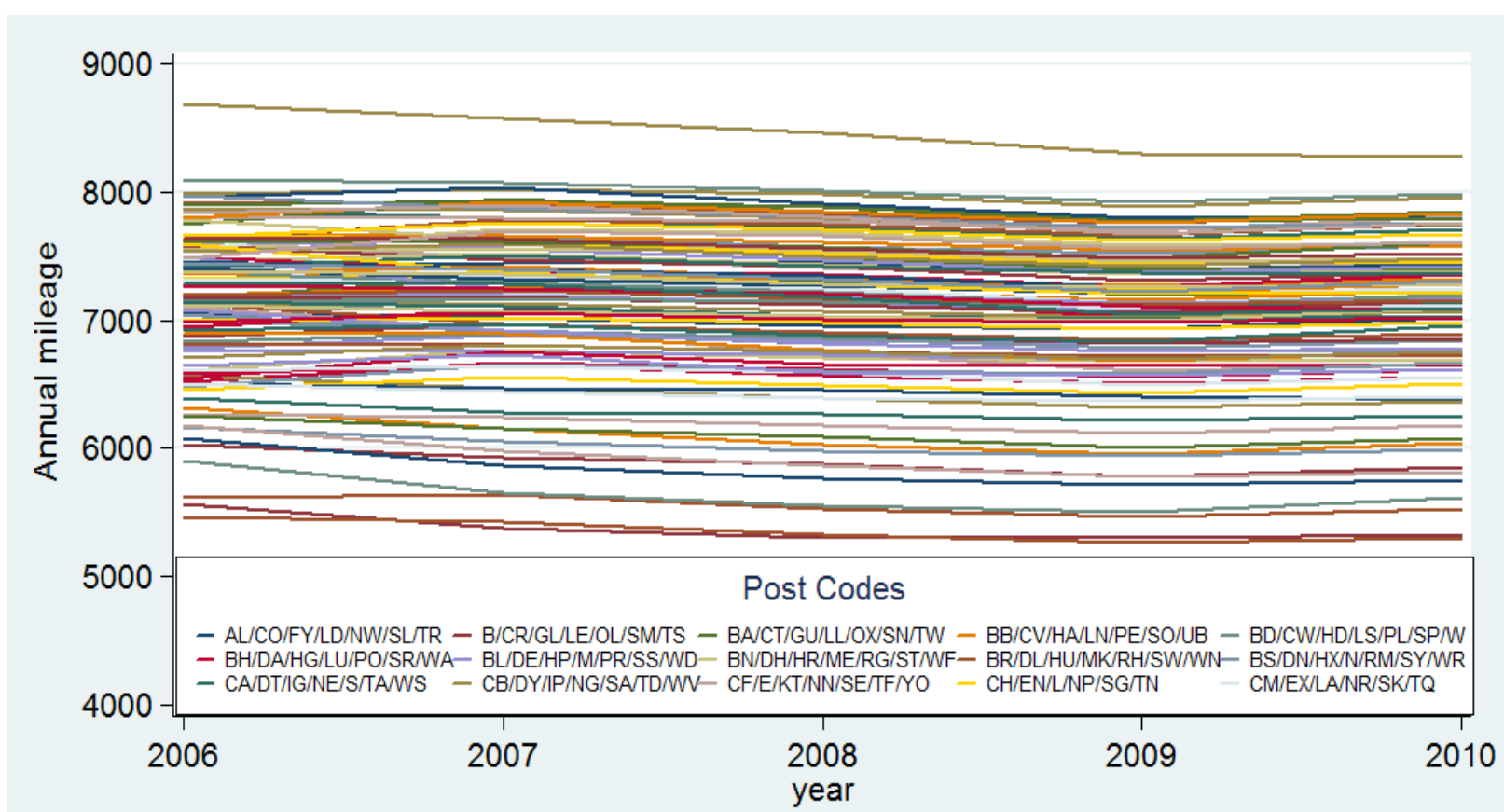

Figure 2: Annual VMT per car per region

\section{Model Specification and Estimation Results}

\section{1. $\quad$ Model specification and Base Model Results}

The specification of the VMT models include price and income effects, availability of other transport modes, motorization rate, low speed and congestion effects, petrol supply infrastructure availability, "engine size and fuel consumption" effects. Table 2 provides the expected effects of the variables included in the model, according to economic theory. 
Table 1: Descriptive statistics of the data

\begin{tabular}{|c|c|c|c|c|c|c|c|}
\hline Variable & Variable Definition & Data Source(s) & Units & Mean & Std.Dev. & Min & Max \\
\hline VMT & $\begin{array}{l}\text { Vehicle Miles Travelled (VMT) per car } \\
\text { per area }\end{array}$ & MOT & miles & 7083 & 608 & 5264 & 8683 \\
\hline $\mathrm{LN}(\mathrm{VMT})$ & & MOT & miles & 8.86 & 0.09 & 8.57 & 9.06 \\
\hline Disposable Income & Disposable Income per household/area & ONS & $£$ & 14425 & 2479 & 10759 & 27091 \\
\hline LN(Income) & & ONS & $£$ & 9.58 & 0.15 & 9.32 & 10.21 \\
\hline Petrol price & Petrol price per area & Experia Catalist & $£$ & 102.0 & 9.1 & 90.0 & 119.0 \\
\hline LN(Petrol price) & & Experia Catalist & $£$ & 4.59 & 0.06 & 4.50 & 4.69 \\
\hline LN(Petrol price max) & Petrol price maximum, $x_{i t}^{r}$, per area & Experia Catalist & $£$ & 4.58 & 0.08 & 4.45 & 4.69 \\
\hline LN(Petrol price recovery) & Petrol price recovery, $x_{i t}^{r}$, per area & Experia Catalist & $£$ & 0.57 & 1.14 & 0.00 & 2.90 \\
\hline LN(Price cum. reductions) & $\begin{array}{l}\text { Petrol price cumulative reductions, } x_{i t}^{c} \text {, } \\
\text { per area }\end{array}$ & Experia Catalist & $£$ & -0.40 & 0.80 & -2.10 & 0.00 \\
\hline LN(Petrol station number) & Petrol station number per area & Experia Catalist & count & 4.03 & 0.57 & 1.39 & 5.30 \\
\hline Metro/underground & Metro/underground interchange area & NaPTAN & dummy & 0.45 & 0.50 & 0.00 & 1.00 \\
\hline LN(Rail) & Rail stations per hectare per area & NaPTAN/Census & count & -10.24 & 0.58 & -12.00 & -8.25 \\
\hline LN(Bus) & Bus stops per hectare per area & NaPTAN/Census & count & -3.39 & 0.95 & -6.34 & -1.26 \\
\hline LN(Low speed proxy) & Fuel consumed per lane mile/area & NaPTAN/ITNL & liters/mile & 15.94 & 0.19 & 14.96 & 16.35 \\
\hline LN(Motorization rate) & Number of cars per capita per area & MOT/Census & rate & -6.18 & 0.78 & -7.89 & -4.17 \\
\hline $\begin{array}{l}\text { LN(Engine size \& fuel } \\
\text { consumption interaction) }\end{array}$ & Engine sizexfuel volume per car/area & MOT/Experia & cc $\times$ liters & -0.86 & 0.27 & -1.77 & 1.04 \\
\hline $\mathrm{LN}(\mathrm{AFU}$ proxy) & Alternative fuel use (AFU) proxy per area & MOT/Experia & liters & 6.13 & 0.53 & 4.01 & 8.20 \\
\hline
\end{tabular}


Table 2: Variable description, data sources, and expected effects

\begin{tabular}{ll}
\hline Variable name & Expected Effect (expected sign) \\
\hline LN(VMT) & Dependent variable \\
LN(Income) & Income (+) \\
LN(Petrol price) & Price (-) \\
LN(Petrol price max) & Price reversibility (-) \\
LN(Petrol price recovery) & Price reversibility (-) \\
LN(Price cum. reductions) & Price reversibility (-) \\
LN(Petrol station number) & Refueling access, rurality (-) \\
Metro/underground & PT not in road network (-) \\
LN(Rail) & PT not in road network (-) \\
LN(Bus) & PT in road network (- or +) \\
LN(Low speed proxy) & Low speed proxy (-) \\
LN(Motorization rate) & Car dependency (+) or car use intensity (-) \\
LN(Engine size \& fuel consumption) & Engine size and fuel consumption interaction (+) \\
LN(AFU proxy) & Population segment effect (- or +) \\
\hline
\end{tabular}

The results of the base fixed effects panel model (FE1) in equation 1 are presented in Table 3. The overall fit is quite good for this type of model, explaining over $80 \%$ of the variation in the data. Most coefficients are statistically significant and their signs are indeed according economic theory expectations.

Income and price effects are statistically significant and inelastic. Figure 1 illustrates the trend of rising engine size; the "engine size \& fuel consumption" captures the interaction effect on VMT of car with larger engines and higher fuel consumption. This interaction has a significant positive effect to VMT, as expected.

Changes in the petrol supply infrastructure are an important factor that affects VMT. Sparsely distributed petrol stations can affect the ease of access for refueling, resulting to longer trips and higher VMT, as reflected in the negative coefficient of the base model. The problem of too few, very sparsely located petrol stations, reducing in number in rural areas has been raised by the popular press (Collins, 2014) and is referred to as "Fuel Deserts". This variable might also partly capture the levels of urbanization that cannot otherwise be fully accounted for, as the use of strictly cross-sectional census data on population density is impossible in a fixed effects panel model. 
Metro/underground and rail, are expected in principle to operate in competition to car mileage. This may not necessarily be the case for buses using the same infrastructure as cars. Increased bus use may not affect adversely VMT, as it can operate complementary in some cases by different population groups. The importance of explicitly accounting for the spatial interactions, when looking at public transport effects to VMT, is illustrated in the next section, as no public transport coefficients are statistically significant in the base model.

AFU proxy controls for the subgroup of consumers, who may travel more due to vehicles' increased energy efficiency or display a propensity of reduced car use, due to smaller engine vehicles mainly used for urban trips. The AFU proxy coefficient is negative, thus a high proportion of alternative fuel vehicle, in their vast majority hybrid, does not result into a rebound effect due to increased energy efficiency, rather a propensity of less car use. It is also stressed that this result may be affected by electric vehicle use that has a limited range.

Ceteris paribus, the fuel consumed per lane mile is expected to be higher in areas suffering from congested roads, but it could also capture a road network, in which vehicles are constrained to low speeds and higher fuel consumption (e.g. no motorways, too many traffic calming measures). These are reflected in the significant negative coefficient of this variable.

The base FE1 model scope is primarily to ascertain data properties that allow the estimation of spatial models in section 4.2. Hence, a number of statistical test results are presented in Table 3. The Hausman tests point to a fixed effects model rather than random, which precludes the use of census data that are strictly cross-sectional. The Wooldridge test show that an autoregressive term should be included in the estimation. The normality of the residual cannot be rejected, thus there should not be any issues with the use of maximum likelihood (ML). All relevant tests reject the hypothesis of no spatial dependence. The Lagrange multiplier (LM) tests (Anselin et al. 2008) reject a SAR type of spatial interaction in favor of SEM (see test limitations in Table 3 footnote). Conversely, Pirotte and Madre (2011) present the results of both SAR and SEM, with no clear justification on the selection process between the two. The model selection process will require further testing, as SEM is a constrained version of SDM. 
FE2 model is identical to the FE1 except for the inclusion of the decomposed price elements in equations 14-16, instead of a single variable. These effects are indeed statistically significant and improve the overall fit of the model, showing that there is empirical support for asymmetries and hysteresis.

\section{2. $\quad$ Dynamic Spatial Durbin Model Results}

The estimation results of the dynamic SDM specification are also presented in Table 3. A substantial improvement in the overall goodness of fit (reflected by AIC and BIC) is observed for spatial models, compared to the respective base models, while the coefficients remain relatively stable across specifications. The key estimation issue, of dynamic spatial panel models satisfying the stability condition: $\lambda+\rho+\gamma<1$ (Elhorst, 2014), is present here.

The Wald test 1 in Table 3 rejects the restriction of SEM in favor of SDM (see test restrictions in Table 3 footnote). The Wald test 2 shows that $\mathbf{W X} \boldsymbol{\theta}^{14}$ is statistically significant, thus rejecting the SAR in favor of SDM. We cannot reject the null hypothesis that $\gamma=0$ in SDM1, providing some empirical support to the contention of limited economic significance for the spatiotemporal lag in this context. SDM1 overall fit to the data is worse than SDM2, and given their similarity, SDM1 results are not discussed any further.

Interestingly, the negative trend in VMT is statistically significant across all models, after having controlled for motorization rate. Both SDM2 and SDM3 exhibit highly significant spatial autoregressive parameters $(\rho)$ of 0.57 and 0.45 respectively, which are comparable to the 0.47 of the Pirotte's and Madre's (2011) fixed effects SAR model. Furthermore, a number of independent variables with significant $\theta$ s demonstrate the substantial spatial patterns affecting

\footnotetext{
${ }^{14} \mathbf{W X \boldsymbol { \theta }}$ captures the effect of changing an independent variable in a particular area on the dependent variables of all the neighbouring areas. Hence, only variables that are expected to have spatial effects on neighbouring VMT were included, such as the public transport infrastructure, fuel price, motorisation rate, and the low speed proxy. The "Metro/underground interchange area" is a dummy variable and as such was not included. Price cumulative reductions and recovery, income, and petrol station number were

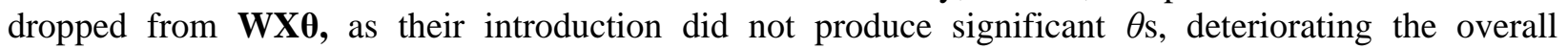
goodness of fit.
} 
VMT that would otherwise go amiss and introduce bias to other types of models. This is best illustrated by the coefficients of public transport that are not statistically significant in the base model, but gain significance in the spatial models. SDM3 is identical to SDM2, except for the introduction of asymmetries and hysteresis in equations 14-16. The better overall fit of SDM3, compared to FE2 and SDM2, suggests that spatial specification with the decomposed price elements captures additional variation in the data.

Wald tests 3 to 9 are employed to ascertain the statistical significance of price asymmetry and/or hysteresis. In both FE2 and SDM 3, Wald test 3 rejects the difference between the three price components coefficients being zero, showing that the price effect on VMT is not completely reversible after a price shift. Wald test 4 shows that asymmetry between price reductions and recovery is statistically significant in both models. The differences between maximum price levels and price recovery are not significant in Wald test 6, denoting no significant hysteresis. However, a "spatial" hysteresis becomes significant by the introduction of the spatial component of maximum price levels, as shown in Wald test 8. The price effect on VMT is also not reversible in a spatial setting after a price shift, as shown in Wald test 9. Wald tests 7-9 are only possible in SDM3, demonstrating that price reversibility, asymmetry, and hysteresis have indeed a significant impact, a big part of which is overlooked if the spatial dimension is ignored.

Section 2.1 illustrated that the $\beta$ s in Table 3 would not be directly interpretable as magnitudes of explanatory variable effects. Therefore, the partial derivative for each independent variable is estimated from equations 12-13 to produce the direct, indirect, and total short-run, and long-run elasticities in Table 4.

Starting the discussion from SDM2, the low speed proxy, alternative fuel use proxy and number of petrol stations have significant indirect elasticities that contribute to their increased magnitude compared to the base model. The direct short-term price elasticity of -0.09 is close to the base model and to the elasticity of -0.094 in Pirotte and Madre (2011). There is no significant indirect price elasticity in SDM2. The total short-term price elasticity of -0.087 is also consistent with the non-spatial literature, for example, the -0.026 elasticity in Hymel et al (2010), and the range of 0.06 to -0.33 in the review of Goodwin et al. (2004). 
Table 3: Results-Spatial Diffusion and Asymmetries

\begin{tabular}{|c|c|c|c|c|c|}
\hline & $\begin{array}{c}\text { FE1: } \\
\text { Base Model }\end{array}$ & $\begin{array}{c}\text { FE2: } \\
\text { Price asymmetries }\end{array}$ & $\begin{array}{c}\text { SDM1: Spatial \& } \\
\text { Spatiotemporal lags }\end{array}$ & $\begin{array}{c}\text { SDM2: } \\
\text { Spatial diffusion }\end{array}$ & $\begin{array}{c}\text { SDM3: Spatial diffusion } \\
\text { \& asymmetries }\end{array}$ \\
\hline Dependent variable: LN(VMT) & Coef. (SE). & Coef. (SE). & Coef. (SE) & Coef. (SE). & Coef. (SE) \\
\hline \multicolumn{6}{|l|}{$\boldsymbol{\beta}$ : Independent Variable coefficients } \\
\hline$\beta_{1}:$ Trend & $-0.020(0.003)^{* * *}$ & $-0.0245(0.0024)^{\star \star \star}$ & $-0.0090(0.0034)^{\star \star *}$ & $-0.0084(0.0034)^{\star *}$ & $-0.0138(0.0035)^{* \star \star}$ \\
\hline$\beta_{2}: \mathrm{LN}($ Income $)$ & $0.045(0.020)^{* *}$ & $-0.0193(0.0200)$ & $0.0313(0.0146)^{\star *}$ & $0.0343(0.0137)^{\star *}$ & $0.0053(0.0153)$ \\
\hline$\beta_{3}: \mathrm{LN}($ Petrol price $)$ & $-0.087(0.005)^{* * *}$ & & $-0.0882(0.0417)^{\star \star}$ & $-0.0885(0.0417)^{\star *}$ & \\
\hline$\beta_{4}: \mathrm{LN}($ Petrol price max $)$ & & $-0.0209(0.0098)^{\star *}$ & & & $-0.0831(0.0419)^{* *}$ \\
\hline$\beta_{5}: \mathrm{LN}$ (Petrol price recovery) & & $-0.0258(0.0075)^{\star \star \star}$ & & & $-0.0261(0.0056)^{* \star *}$ \\
\hline$\beta_{6}: \mathrm{LN}$ (Petrol price cum. reductions) & & $-0.0433(0.0108)^{\star \star \star}$ & & & $-0.0410(0.0080)^{* \star *}$ \\
\hline$\beta_{7}: \mathrm{LN}($ Petrol station number) & $-0.021(0.009)^{\star *}$ & $-0.0074(0.0084)$ & $-0.0150(0.0060)^{* *}$ & $-0.0153(0.0060)^{\star *}$ & $-0.0058(0.0061)$ \\
\hline$\beta_{8}:$ Metro/underground & $0.000(0.001)$ & $-0.0013(0.0008)$ & $-0.0009(0.0006)$ & $-0.0009(0.0006)$ & $-0.0014(0.0006)^{\star *}$ \\
\hline$\beta_{9}: \mathrm{LN}(\mathrm{AFU}$ proxy) & $-0.002(0.001)^{\star *}$ & $-0.0027(0.0009)^{\star \star \star}$ & $-0.0022(0.0007)^{\star \star *}$ & $-0.0022(0.0007)^{\star \star *}$ & $-0.0024(0.0007)^{* \star *}$ \\
\hline$\beta_{10}: \mathrm{LN}(\mathrm{Bus})$ & $0.003(0.002)$ & $0.0014(0.0018)$ & $0.0030(0.0014)^{\star *}$ & $0.0030(0.0014)^{\star *}$ & $0.0032(0.0014)^{\star \star}$ \\
\hline $\begin{array}{l}\beta_{11}: \text { LN(Engine size } \& \text { fuel } \\
\text { consumption) }\end{array}$ & $0.557(0.166)^{\star \star \star}$ & $0.1388(0.1587)$ & $0.3054(0.1165)^{\star \star \star}$ & $0.3134(0.1156)^{\star * \star}$ & $0.1558(0.1193)$ \\
\hline$\beta_{12}: \mathrm{LN}($ Motorization rate) & $0.121(0.020)^{\star \star \star}$ & $0.0810(0.0190)^{\star \star \star}$ & $0.0781(0.0154)^{\star \star \star}$ & $0.0791(0.0153)^{\star \star \star}$ & $0.0761(0.0151)^{\star \star \star}$ \\
\hline$\beta_{13}:$ LN(Low speed proxy) & $-0.579(0.163)^{* * *}$ & $-0.1361(0.1577)$ & $-0.3128(0.1168)^{\star \star \star}$ & $-0.3205(0.1159)^{\star \star \star}$ & $-0.1589(0.1196)$ \\
\hline$\beta_{14}:$ LN(Rail) & $-0.007(0.005)$ & $-0.0056(0.0044)$ & $0.0009(0.0036)$ & $0.0008(0.0036)$ & $0.0008(0.0035)$ \\
\hline Fixed-effects mean & -4.198 & 5.0765 & -4.275 & -4.727 & -0.0280 \\
\hline$\sigma^{2}(\varepsilon)$ & $0.349(0.004)^{* * *}$ & $6.8 \mathrm{E}-02(3.6 \mathrm{E}-03)^{\star * *}$ & $8.3 \mathrm{E}-06(5.2 \mathrm{E}-07)^{\star * *}$ & $8.2 \mathrm{E}-06(5.3 \mathrm{E}-07)^{\star * *}$ & $8.1 \mathrm{E}-06(5.1 \mathrm{E}-07)^{\star \star *}$ \\
\hline \multicolumn{6}{|l|}{ Temporal Autoregressive $\left(\lambda \mathbf{y}_{\mathrm{t}-1}\right)$} \\
\hline$\lambda:$ LN(VMT) at $t-1$ & $0.082(0.027)^{\star * \star}$ & $0.1241(0.0250)^{\star \star \star}$ & $0.1279(0.0204)^{\star \star \star}$ & $0.1222(0.0178)^{\star * \star}$ & $0.1423(0.0182)^{\star \star \star}$ \\
\hline \multicolumn{6}{|l|}{ Spatial Autoregressive $\left(\rho \mathbf{W} \mathbf{y}_{t}\right)$} \\
\hline$\rho:$ LN(VMT) & & & $0.5670(0.0548)^{\star \star \star}$ & $0.5725(0.0548)^{\star \star \star}$ & $0.4493(0.0634)^{\star \star \star}$ \\
\hline$\gamma: \mathrm{LN}(\mathrm{VMT})$ at $t-1$ & & & $-0.0252(0.0412)$ & & \\
\hline \multicolumn{6}{|l|}{ 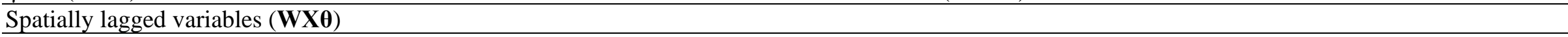 } \\
\hline$\theta_{1}: \mathrm{LN}($ Petrol price $)$ & & & $0.0507(0.0423)$ & $0.0512(0.0423)$ & \\
\hline$\theta_{2}:$ LN(Petrol price max $)$ & & & & & $0.0770(0.0431)^{*}$ \\
\hline$\theta_{3}: \mathrm{LN}(\mathrm{Bus})$ & & & $-0.0014(0.0041)$ & $-0.0012(0.0041)$ & $-0.0083(0.0042)^{* *}$ \\
\hline$\theta_{4}:$ LN(Low speed Proxy) & & & $-0.0295(0.0172)^{*}$ & $-0.0334(0.0161)^{* *}$ & $0.0019(0.0169)$ \\
\hline$\theta_{5}: \mathrm{LN}($ Motorization rate) & & & $-0.0079(0.0375)$ & $-0.0150(0.0365)$ & $-0.0419(0.0380)$ \\
\hline$\theta_{6}:$ LN(Rail) & & & $-0.0240(0.0088)^{\star * *}$ & $-0.0236(0.0088)^{\star \star *}$ & $-0.0236(0.0089)^{* * *}$ \\
\hline
\end{tabular}




\begin{tabular}{|c|c|c|c|c|c|}
\hline & $\begin{array}{c}\text { FE1: } \\
\text { Base Model }\end{array}$ & $\begin{array}{c}\text { FE2: } \\
\text { Price asymmetries }\end{array}$ & $\begin{array}{c}\text { SDM1: Spatial \& } \\
\text { Spatiotemporal lags }\end{array}$ & $\begin{array}{c}\text { SDM2: } \\
\text { Spatial diffusion }\end{array}$ & $\begin{array}{c}\text { SDM3: Spatial diffusion } \\
\text { \& asymmetries }\end{array}$ \\
\hline $\mathrm{AIC} \& \mathrm{BIC}$ & $-3493 \&-3441$ & $-3579 \&-3518$ & $-3591 \&-3511$ & $-3592 \&-3516$ & $-3626 \&-3542$ \\
\hline LL(model) & 1759 & 1804 & 1815 & 1815 & 1834 \\
\hline $\mathrm{R}^{2}$ within & 0.8132 & 0.8498 & & & \\
\hline \multicolumn{6}{|l|}{ Base Model Tests } \\
\hline Hausman test, H0: Random effects^ & $321.40^{* \star *}$ & $301.52^{\star * *}$ & $\wedge 86.34^{\star * *}$ & $\wedge 86.34^{\star \star \star}$ & $\wedge 90.67^{\star \star \star}$ \\
\hline $\begin{array}{l}\text { Wooldridge test (no autoregressive } \\
\text { term) H0: No autocorrelation }\end{array}$ & $88.405^{\star \star \star}$ & & & & \\
\hline Harris-Tzavalis unit-root test, H0: & & & & & \\
\hline unit-root (Small-sample adjustment) & $0.1752^{\star n}$ & & & & \\
\hline Jarque-Bera LM Test, H0: Normality & 3.5462 & & & & \\
\hline Moran MI, H0: No Spatial & & & & & \\
\hline Dependence & $0.3838^{\star * \star}$ & & & & \\
\hline Geary, H0: No Spatial Dependence & $0.6011^{\star \star \star}$ & & & & \\
\hline Getis-Ords, H0: No Spatial & & & & & \\
\hline Dependence & $-2.3513^{\star \star \star}$ & & & & \\
\hline LM test, Spatial Error^^^ & $70.53^{\star \star \star}$ & & & & \\
\hline Robust LM test, Spatial Error ${ }^{\wedge \wedge}$ & $70.58^{\star \star \star}$ & & & & \\
\hline LM test, Spatial $\mathrm{Lag}^{\wedge \wedge}$ & 0.0004 & & & & \\
\hline Robust LM test, Spatial Lag^^ & 0.0524 & & & & \\
\hline \multicolumn{6}{|l|}{ Wald Tests on SDM models } \\
\hline Wald test $1, \mathrm{H} 0: \boldsymbol{\theta}+\rho \boldsymbol{\beta}=0^{\wedge \wedge \wedge}$ & & & $21.98^{\star \star \star}\left(34.38^{\star \star \star}\right)$ & $21.95^{\star \star \star}\left(38.94^{\star \star \star}\right)$ & $16.21^{\star \star \star}\left(30.35^{\star \star \star}\right)$ \\
\hline Wald test 2, H0: $\boldsymbol{\theta}=0$ & & & $12.36^{\star \star}$ & $13.17^{\star \star \star}$ & $16.18^{\star \star \star}$ \\
\hline Wald test $3, \mathrm{H} 0: \beta_{4}=\beta_{5}=\beta_{6}$ & & $22.87^{\star \star \star}$ & & & $38.14^{\star \star \star}$ \\
\hline Wald test $4, \mathrm{H} 0: \beta_{5}=\beta_{6}$ & & $28.54^{* \star \star}$ & & & $36.02^{\star \star \star}$ \\
\hline Wald test $5, \mathrm{H} 0: \beta_{4}=\beta_{6}$ & & 0.17 & & & 1.88 \\
\hline Wald test $6, \mathrm{H} 0: \beta_{4}=\beta_{5}$ & & 2.37 & & & 1.02 \\
\hline Wald test $7, \mathrm{H} 0: \beta_{4}=\beta_{6}=\theta_{2}$ & & & & & $12.72^{\star \star \star}$ \\
\hline Wald test $8, \mathrm{H} 0: \beta_{4}=\beta_{5}=\theta_{2}$ & & & & & $18.85^{\star \star \star}$ \\
\hline Wald test 9, H0: $\beta_{4}=\beta_{5}=\beta_{6}=\theta_{2}$ & & & & & $46.45^{\star \star \star}$ \\
\hline
\end{tabular}

Wald test 9, H0: $\beta_{4}=\beta_{5}=\beta_{6}=\theta$

${ }^{* * *}$ significant at $\mathrm{p}<0.01 ;{ }^{* *}=$ significant at $\mathrm{p}<0.05 ;{ }^{*}=$ significant at $\mathrm{p}<0.10 .{ }^{\wedge}$ Dynamic random-effects spatial models cannot be currently estimated, hence the test is conducted on the equivalent static spatial models. ${ }^{\wedge}$ The respective LM tests for dynamic spatial panel models have not yet been derived, thus we employ the LM tests in Anselin et al. (2008) for static pooled spatial panel model. ${ }^{\wedge \wedge}$ The test in the brackets refers to the full WXO in equation 8 that includes all the independent variables and correctly rejects SEM in favor of SDM. 
Income has a statistically significant indirect spatial effect in SDM2 that contributes to a higher total income elasticity of 0.082 compared to 0.045 in the base model. This inelastic income effect is a bit higher to studies reviewed by Goodwin et al. (2004) showing a range of -0.02 to 0.005 short-term income elasticities. On the other hand, Pirotte and Madre (2011) find a direct shortterm income elasticity of 0.42 and a total short-term income elasticity 0.88 . This is not unexpected given that the GDP indicator they use instead of income would vary significantly over the long time series employed. Moreover, Pirotte and Madre (2011) did not control for temporal autoregressive effects that may bias results if present but not included (Tao and $\mathrm{Yu}$, 2012).

The positive direct elasticity of the motorization rate is significant across all models and around 0.10 , capturing car dependence rather than car use intensity. These findings are consistent with car use saturation. Conversely, Pirotte and Madre (2011) find a motorization rate elasticity of 0.43, which is understandable given the 1973-1999 study period before any car use saturation conditions could have become observable. This could also have contributed to their relatively high income elasticity.

Another striking result is that public transport variables gain statistical significance in the spatial models, confirming the important spatial element of these effects. The bus network density has a statistically weak direct effect that is complementary to VMT. Conversely, the proliferation of rail infrastructure has a significant direct negative effect, and an indirect effect of much higher magnitude than the direct effect. This implies that the effectiveness of rail to compete with car travel is highly dependent on the developed infrastructure of neighboring areas and thus connectivity. This variable remains significant and of similar magnitude across both models, whereas the existence of metro stations only gains significance in SDM3. Other differences between the two models are the "bus" variable dropping out of significance in SDM3, as do income, the "low speed" proxy and the "engine size \& fuel consumption" interaction variable. It seems that the price asymmetry and hysteresis and their spatial components in SDM3 capture a significant part of the data variation. 
The spatial aspects of the decomposed price effect are also of particular interest. The first noteworthy aspect is that the sum of the decomposed parts constitute "more" than the "whole", as the direct price elasticities sum up to -0.148 in SDM3 compared to -0.09 price elasticity in SDM2. This is not the case for the same comparison between the a-spatial models FE1 and FE2. The indirect effects of both price reductions and recovery in SDM3 are statistically significant, contrary to the indirect price effects in SDM2. Surprisingly, the indirect maximum price level effect is positive, but not significant in SDM3. This unexpected result may partly capture a slight increase in mileage when price levels are higher, possibly due to an increased incentive to travel further for searching cheaper petrol prices, which may drop this coefficient out of significance in the total effects of SDM3. Therefore, the combination of the SDM specification with the price decomposition approach provides unique insights on the spatial aspects of price asymmetry and hysteresis.

The magnitude of the temporal autoregressive effects remain relatively low, slightly increasing in SDM3, hence the long-run elasticities in Table 4 are only a bit higher than the short-run. The shortness of the time-series may potentially contribute to this. It would be very interesting to see how temporal patterns interact with the spatial effects in long time-series. The direct long-run price elasticity in SDM2 is -0.105 and SDM3 would provide a long-run elasticity of -0.18 , if we were to sum up all the decomposed parts. Total long-run price elasticity increases in SDM2 to 0.124 , but the price elasticities in SDM3 slightly reduce (-0.166) as maximum price level effect drops from significance. This is potentially due to the spatial issue of searching for cheap petrol discussed in the previous paragraph. Debarsy et al. (2012) also noted such issues in dynamic SDM on cigarette consumption data, as positive indirect long-run price elasticities, attributed to bootlegging, ameliorated the negative direct long-run direct price effects, resulting to significantly lower long-run total price elasticities.

The long-run price elasticities in both SDM2 (-0.124) and SDM3 (-0.166) are consistent to the 0.131 long-run VMT elasticity with respect to per mile fuel cost in Hymel et al (2010). Thea are also within the -0.55 and -0.11 range reported by Goodwin et al. (2004). The long-run income elasticity of 0.116 in SDM2 is also consistent but on the low side of the mean elasticity of 0.17 (range 0.00-0.4) reported in Goodwin et al. (2004). 
Table 4: Short-run and Long-run Elasticities from the preferred SDM Specifications

\begin{tabular}{|c|c|c|c|c|}
\hline \multirow[b]{2}{*}{ Direct Elasticities } & \multicolumn{2}{|c|}{ SDM 2: Spatial diffusion } & \multicolumn{2}{|c|}{$\begin{array}{l}\text { SDM 3: Spatial diffusion \& price } \\
\text { asymmetries }\end{array}$} \\
\hline & $\begin{array}{l}\text { Short-run } \\
\text { Elast. }\left(\mathrm{SE}^{\wedge}\right)\end{array}$ & $\begin{array}{l}\text { Long-run } \\
\text { Elast. }\left(\mathrm{SE}^{\wedge}\right)\end{array}$ & $\begin{array}{l}\text { Short-run } \\
\text { Elast. }\left(\mathrm{SE}^{\wedge}\right)\end{array}$ & $\begin{array}{l}\text { Long-run } \\
\text { Elast. }\left(\mathrm{SE}^{\wedge}\right)\end{array}$ \\
\hline Income & $0.041(0.016)^{\star \star \star}$ & $0.050(0.019)^{\star \star \star}$ & $0.006(0.016)$ & $0.008(0.020)$ \\
\hline Petrol price & $-0.090(0.035)^{\star \star *}$ & $-0.105(0.041)^{\star \star \star}$ & & \\
\hline Petrol price max. & & & $-0.073(0.035)^{\star *}$ & $-0.086(0.041)^{\star *}$ \\
\hline Petrol price recoverv & & & $-0.029(0.006)^{\star \star \star}$ & $-0.035(0.008)^{\star \star \star}$ \\
\hline Price cum. reductions & & & $-0.046(0.009)^{\star \star \star}$ & $-0.056(0.011)^{\star \star \star}$ \\
\hline Petrol station number & $-0.018(0.007)^{\star \star \star}$ & $-0.022(0.008)^{\star \star \star}$ & $-0.006(0.007)$ & $-0.008(0.008)$ \\
\hline Metro/underground ${ }^{\wedge \wedge}$ & $-0.001(0.001)^{\star *}$ & $-0.001(0.001)$ & $-0.002(0.001)^{\star *}$ & $-0.002(0.001)^{* *}$ \\
\hline AFU proxv & $-0.003(0.001)^{* * *}$ & $-0.003(0.001)^{* * *}$ & $-0.003(0.001)^{\star * *}$ & $-0.003(0.001)^{\star \star \star}$ \\
\hline Bus & $0.003(0.002)^{*}$ & $0.004(0.002)^{\star}$ & $0.001(0.002)$ & $0.001(0.002)$ \\
\hline Engine size \& fuel cons. & $0.373(0.128)^{* * *}$ & $0.447(0.154)^{\star \star \star}$ & $0.175(0.135)$ & $0.211(0.163)$ \\
\hline Motorization rate & $0.089(0.016)^{\star \star \star}$ & $0.106(0.020)^{\star \star \star}$ & $0.074(0.016)^{* * *}$ & $0.088(0.020)^{\star \star \star}$ \\
\hline Low speed proxv & $-0.393(0.128)^{\star * *}$ & $-0.473(0.154)^{\star * *}$ & $-0.178(0.134)$ & $-0.214(0.162)$ \\
\hline Rail & $-0.007(0.004)^{*}$ & $-0.010(0.005)^{\star *}$ & $-0.006(0.004)^{\star}$ & $-0.008(0.004)^{*}$ \\
\hline Indirect Elasticities & Short run & Long Run & Short run & Long Run \\
\hline Income & $0.040(0.017)^{\star \star}$ & $0.066(0.031)^{\star \star}$ & $0.004(0.010)$ & $0.006(0.017)$ \\
\hline Petrol price & $0.002(0.036)$ & $-0.018(0.043)$ & & \\
\hline Petrol price max. & & & $0.061(0.038)$ & $0.070(0.046)$ \\
\hline Petrol price recovery & & & $-0.018(0.006)^{\star \star *}$ & $-0.029(0.010)^{\star \star \star}$ \\
\hline Price cum. reductions & & & $-0.028(0.009)^{\star \star *}$ & $-0.046(0.016)^{\star \star \star}$ \\
\hline Petrol station number & $-0.018(0.008)^{* *}$ & $-0.029(0.014)^{* *}$ & $-0.004(0.005)$ & $-0.007(0.008)$ \\
\hline Metro/underground $^{\wedge \wedge}$ & $-0.001(0.001)$ & $-0.002(0.002)$ & $-0.001(0.000)^{*}$ & $-0.002(0.001)^{*}$ \\
\hline AFU proxv & $-0.003(0.001)^{\star *}$ & $-0.004(0.002)^{*}$ & $-0.002(0.001)^{\star *}$ & $-0.003(0.001)^{\star *}$ \\
\hline Bus & $0.000(0.008)$ & $0.001(0.012)$ & $-0.011(0.006)^{*}$ & $-0.014(0.009)$ \\
\hline Engine size \& fuel cons. & $0.364(0.155)^{\star \star}$ & $0.605(0.297)^{\star *}$ & $0.108(0.091)$ & $0.174(0.153)$ \\
\hline Motorization rate & $0.057(0.060)$ & $0.100(0.086)$ & $-0.011(0.054)$ & $-0.004(0.073)$ \\
\hline Low speed proxv & $-0.441(0.161)^{\star \star *}$ & $-0.719(0.317)^{\star *}$ & $-0.108(0.093)$ & $-0.175(0.155)$ \\
\hline Rail & $-0.046(0.016)^{\star * *}$ & $-0.067(0.024)^{\star * *}$ & $-0.036(0.013)^{\star * *}$ & $-0.049(0.019)^{\star * \star}$ \\
\hline Total Elasticities & Short run & Long Run & Short run & - Long Run \\
\hline Income & $0.082(0.032)^{\star \star \star}$ & $0.116(0.048)^{* *}$ & $0.010(0.0267)$ & $0.014(0.037)$ \\
\hline Petrol price & $-0.087(0.010)^{\star \star *}$ & $-0.124(0.017)^{\star \star *}$ & & \\
\hline Petrol price max. & & & $-0.012(0.015)$ & $-0.016(0.021)$ \\
\hline Petrol price recoverv & & & $-0.047(0.011)^{\star \star *}$ & $-0.064(0.016)^{\star * \star}$ \\
\hline Price cum. reductions & & & $-0.075(0.016)^{\star * *}$ & $-0.102(0.024)^{\star * \star}$ \\
\hline Petrol station number & $-0.036(0.014)^{\star \star}$ & $-0.051(0.021)^{\star \star}$ & $-0.011(0.011)$ & $-0.014(0.016)$ \\
\hline Metro/underground ${ }^{\wedge \wedge}$ & $-0.002(0.002)$ & $-0.003(0.002)$ & $-0.003(0.001)^{\star *}$ & $-0.004(0.002)^{* *}$ \\
\hline AFU proxv & $-0.005(0.002)^{\star \star *}$ & $-0.007(0.003)^{\star *}$ & $-0.004(0.001)^{\star \star \star}$ & $-0.006(0.002)^{* * *}$ \\
\hline Bus & $0.004(0.009)$ & $0.005(0.013)$ & $-0.009(0.007)$ & $-0.013(0.010)$ \\
\hline Engine size \& fuel cons. & $0.737(0.271)^{\star \star \star}$ & $1.052(0.426)^{\star *}$ & $0.283(0.223)$ & $0.385(0.309)$ \\
\hline Motorization rate & $0.147(0.068)^{\star *}$ & $0.207(0.097)^{\star *}$ & $0.063(0.061)$ & $0.084(0.083)$ \\
\hline Low speed proxv & $-0.834(0.272)^{\star \star *}$ & $-1.192(0.438)^{\star \star *}$ & $-0.286(0.220)$ & $-0.389(0.307)$ \\
\hline Rail & $-0.054(0.018)^{\star \star \star}$ & $-0.076(0.027)^{\star \star *}$ & $-0.042(0.015)^{\star \star \star}$ & $-0.057(0.021)^{\star \star \star}$ \\
\hline
\end{tabular}




\section{Conclusions}

Since car travel takes place across space and time, any comprehensive analysis of car use should take into account these two dimensions. The dynamic SDM specification introduced here, provides a robust and flexible methodological framework to capture the spatial and temporal aspects of car travel, exhibiting the following advantages compared to "a-spatial" and/or standard spatial models. First, the dynamic SDM allows testing for constraints that result in SEM or SAR forms. Second, this specification minimizes potential biases and issues of nonidentification that are prevalent in spatial econometric models. Third, the dynamic SDM is one of the very few feasible spatial models (Elhorst, 2014) that allow the novelty of examining the spatial components of asymmetry and hysteresis, in both the short-run and long-run.

The applicability of this methodological framework is demonstrated in the context of subregional car use demand for England and Wales. A unique dataset, based on the "official" recordings of car mileage in combination with data from a range of public sources, is analyzed. Despite the data limitations of short temporal coverage and restricted spatial information, the dynamic SDM specification produces compelling results. In addition to long-run price and income elasticities of -0.124 and 0.116 respectively that are broadly consistent with the literature, the spatial aspects of petrol price are of particular interest. The reaction to price changes indeed exhibits asymmetries that potentially indicate loss aversion and reference dependence. Hysteresis that can reflect habits and inertia is significant only when a spatial component is included. The spatial aspects of imperfect price reversibility capture otherwise "unseen" sources of variation in the data, and the sum of the price components are found to constitute more than the "whole".

Another striking result is that the effect of public transport infrastructure on car travel is significant only in the spatial models, emphasizing the importance of including the spatial dimension when analyzing such effects. The findings are also consistent with car use saturation, as the positive effects of the motorization rate capture car dependence rather than car use intensity. The proxy for low speed traffic that is partly affected by congestion has significant negative elasticities with respect to VMT in SMD2, becoming slightly elastic in the long run. 
This underlines the potential significance of lower speeds and congestion constraints in the longrun "evolution" of car use.

One of the unique features of the analysis is to capture the "fuel desert" effects in rural areas, brought about by the number of petrol stations affecting VMT due to refueling access. VMT is reduced in areas with a high proportion of alternative fuel vehicle. It seems that the subgroup of consumers, who own alternative fuel vehicles, also displays the propensity of decreased car use, which is also true for cars with smaller engines and lower fuel consumption, possibly used mainly for urban trips.

The results provide novel insights to future policy initiatives toward influencing car travel demand. These insights stem not only from the competing and complementary effects of public transport, and the alternative fuel use impact, but also from evidence consistent with car use saturation, supportive of the "fuel desert" hypothesis and the importance of congestion constrains. Other novel aspects with policy implications are: the asymmetric price elasticities; and the significance of the spatial dimension to hysteresis and imperfect price reversibility.

The methodological tools discussed in this paper can be applied to a number of transport research contexts and levels of data aggregation, especially to fuel, car use, and energy/transport demand models. Feeding into this framework, future innovations could capture transport network effects in more advanced spatial matrix specifications. There are rapid developments regarding the spatial matrix construction in other fields, where weight matrices capture a range of complicated data linkage structures in social network settings (Bramoullé et al., 2009), or by space-time decay (Thanos et al., 2015; 2016; Dubé et al., 2017), or by trans-dimensional simulated annealing algorithms for efficient matrix selection (Seya et al., 2013). These tools are ideal for condensing and analyzing large amounts of data, made possible by the recent advances in computational power. This underlines the future innovation potential of traffic-flows from transport models being incorporated into spatial weight matrices. This can also provide support to policy initiatives that explicitly address the dynamic, spatio-temporal, and behavioral issues in current transportation systems. 


\section{References}

Anselin L., J. Le Gallo, H. Jayet, 2008, Spatial panel econometrics, in Matyas, L. and Sevestre, P. (Eds.) The Econometrics of Panel Data, Springer-Verlag, Berlin, Heidelberg, Germany.

Arbia, G., 2011. A Lustrum of SEA: Recent Research Trends Following the Creation of the Spatial Econometrics Association (2007-2011). Spatial Economic Analysis 6(4) 377-395

Bao, Y., Gao, Z., Xu, M., Yang, H., 2014. Tradable credit scheme for mobility management considering travelers' loss aversion. Transportation Research Part E: Logistics and Transportation Review 68, 38-154.

Bhat, C.R., Astroza, S., Hamdi, A.S., 2017. A spatial generalized ordered-response model with skew normal kernel error terms with an application to bicycling frequency. Transportation Research Part B: Methodological 95, 126-148.

Bramoullé, Y., Djebbari, H., Fortin, B., 2009. Identification of peer effects through social networks. Journal of Econometrics 150(1), 41-55

Briant, A., Combes, P.P., Lafourcade, M., 2010. Dots to boxes: Do the size and shape of spatial units jeopardize economic geography estimations? Journal of Urban Economics 67, 287-302

Burridge, P., 1981. Testing for a common factor in a spatial autoregression model. Environment and Planning A 13, 795-800.

Castro, M., Paleti, R., Bhat, C., 2012. A latent variable representation of count data models to accommodate spatial and temporal dependence: application to predicting crash frequency at intersections. Transportation Research Part B 46, 253-272

Colins, N., 2014. Rural areas lose 900 petrol stations. The Telegraph. [Online] 26 Sep. Available at (last accessed 03/06/2015): <http://www.telegraph.co.uk/news/uknews/road-and-railtransport/11123785/Rural-areas-lose-900-petrol-stations.html>.

Costa, F., Gerard F., 2015. Hysteresis and the social cost of corrective policies: evidence from a temporary energy saving program. Available at SSRN (last accessed 01/05/2017): 〈https://ssrn.com/abstract=2666704>

Dargay, J.M., 2007. The effect of prices and income on car travel in the UK. Transportation Research Part A 41, 949-960.

Dargay, J.M., 2001. The effect of income on car ownership: evidence of asymmetry. Transportation Research Part A: Policy and Practice 35(9), 807-821. 
Dargay, J.M., Gatley, D., 1997. The demand for transportation fuels: imperfect pricereversibility? Transportation Research Part B 31 (1), 71-82.

Debarsy, N., Ertur, C. and LeSage, J., 2012. Interpreting Dynamic Space-Time Panel Data Models. Statistical Methodology 9, 158-171.

Department for Transport (DfT), 2013. Analysis of vehicle odometer readings recorded at MOT tests. Statistical Release: Vehicle Licensing Statistics, 13 June 2013, London, UK

Department for Transport (DfT), 2014. National Public Transport Access Nodes (NaPTAN) database, 2003-2014, London, UK. Available at (last accessed 06/06/2015): 〈https://www.gov.uk/government/publications/national-public-transport-access-node-schema >.

Dixit, A., 1989. Entry and exit decisions under uncertainty. Journal of political Economy 97(3), 620-638.

Driver and Vehicle Standards Agency (DVSA), 2013. Ministry of Transport Test (MOT) data, 2005-2013, Department for Transport, Bristol, UK. Available at (last accessed 08/06/2015): < http://data.gov.uk/dataset/anonymised_mot_test $>$.

Dubé, J., Legros, D., Thériault, M., Des Rosiers, F., 2014. A Spatial Difference-in-Differences Estimator to Evaluate the Effect of Change in Public Mass Transit Systems on House Prices. Transportation Research Part B 64, 24-40.

Dubé, J., Legros, D., Thanos, S. (2017), Past price "memory" in the housing market: testing the performance of different spatio-temporal specifications. Spatial Economic Analysis, in press http://dx.doi.org/10.1080/17421772.2018.1395063

Elhorst, J.P., 2010. Dynamic panels with endogenous interaction effects when $\mathrm{T}$ is small. Regional Science and Urban Economics 40, 272-282

Elhorst, J.P., 2014. Spatial econometrics: from cross-sectional data to spatial panels. Springer, Berlin, Germany.

Ewing, R., Hamidi, S., Gallivan, F., Nelson, A.C., Grace, J.B., 2013. Combined Effects of Compact Development, Transportation Investments, and Road User Pricing on Vehicle Miles Traveled in Urbanized Areas. Transportation Research Record 2397, 117-124

Experian Catalist, 2014. Fuel price data. Experian Limited, Nottingham, UK <http://www.catalist.com/Products\%20and\%20Services/Fuel\%20price\%20data.aspx $>$.

Gärling, T., Axhausen, K.W., 2003. Introduction: Habitual travel choice. Transportation 30, 111. 
Gibbons, S., Overman, H. G., 2012. Mostly Pointless Spatial Econometrics?, Journal of Regional Science 52, 172-191

Goodwin, P., 1998. The end of equilibrium. In: Garling, T., Laitila, T., Westin, K. (Eds.), Theoretical Foundations of Travel Choice Modeling. Elsevier, Amsterdam, Netherlands.

Goodwin, P., Dargay, J., Hanly, P., 2004. Elasticities of Road Traffic and Fuel Consumption with Respect to Price and Income: A Review. Transport Reviews 24, 275-92.

Goodwin, P., Van Dender, K., 2013. 'Peak Car' — Themes and Issues, Transport Reviews 33(3), 243-254

Grimal, R., Collet, R., Madre, J.L., 2013. Is the Stagnation of Individual Car Travel a General Phenomenon in France? A Time-Series Analysis by Zone of Residence and Standard of Living, Transport Reviews 33 (3), 291-309.

Hardie, B.G., Johnson, E.J., Fader, P.S., 1993. Modeling loss aversion and reference dependence effects on brand choice. Marketing science 12(4), 378-394.

Hess, S., Rose, J.M., Hensher, D.A., 2008. Asymmetric preference formation in willingness to pay estimates in discrete choice models. Transportation Research Part E: Logistics and Transportation Review 44(5), 847-863.

Hess, S., Stathopoulos, A., Daly, A., 2012. Allowing for heterogeneous decision rules in discrete choice models: an approach and four case studies. Transportation 39, 565-591.

Hymel, K.M., Small, K.A., Van Dender, K., 2010. Induced demand and rebound effects in road transport, Transportation Research Part B 44, 1220-1241.

Kahneman, D., Knetsch, J.L., Thaler, R.H., 1991. Anomalies: The endowment effect, loss aversion, and status quo bias. The Journal of Economic Perspectives 5, 93-206.

Kamargianni, M., Ben-Akiva, M., Polydoropoulou, A., 2014. Integrating Social Interaction into Hybrid Choice Models. Transportation 41(6), 1263-1285.

Kamargianni, M., Li, W., Matyas, M., Schäfer, A., 2016. A critical review of new mobility services for urban transport. Transportation Research Procedia 14, 3294-3303.

Kim, C.W., Phipps, T.T.., Anselin, L., 2003. Measuring the Benefits of Air Quality Improvement: A Spatial Hedonic Approach. Journal of Environmental Economics and Management 45, 24-39 
Lacombe, D. J., LeSage, J. P., 2014. Using Bayesian posterior model probabilities to identify omitted variables in spatial regression models. Papers in Regional Science, http://doi.org/10.1111/pirs.12070

Lee, L. F., Yu, J., 2010. Estimation of spatial autoregressive panel data models with fixed effects. Journal of Econometrics 154(2), 165-185

LeGallo, J., 2002. Économétrie spatiale: 1'autocorrélation spatiale dans les modèles de régression linéaire [Spatial econometrics: Spatial autocorrelation in linear regression models], Économie et prévision 155, 139-157

LeSage, J.P., 2014. What Regional Scientists Need to Know about Spatial Econometrics. The Review of Regional Studies 44, 13-32

LeSage, J. P.,Pace, R. K., 2009. Introduction to Spatial Econometrics. CRC Press, Taylor \& Francis, Roca Buton, USA

Louviere, J.J., Street, D., Burgess, L., Wasi, N., Islam, T., Marley, A.A., 2008. Modeling the choices of individual decision-makers by combining efficient choice experiment designs with extra preference information. Journal of choice modelling 1, 128-164.

Masiero, L., Rose, J.M., 2013. The role of the reference alternative in the specification of asymmetric discrete choice models. Transportation research part E: logistics and transportation review 53, 83-92.

Metz, D., 2010. Saturation of demand for daily travel. Transport Reviews 30(5), 659-674.

Office for National Statistics (ONS), 2011. Census data for England and Wales. Titchfield, UK. < https://www.nomisweb.co.uk/census/2011/data_finder $>$.

Office for National Statistics (ONS), 2014. Names, codes and lookups. ONS Geography portal, Titchfield, UK. <http://www.ons.gov.uk/ons/guide-method/geography/products/names--codesand-look-ups/index.html>.

Office for National Statistics (ONS), 2015. NUTS3 Regional Gross Disposable Household Income, 1997-2013, London, UK.

<http://www.ons.gov.uk/ons/taxonomy/index.html?nscl=Regional+Gross+Disposable+Househol d+Income\#tab-data-tables $>$.

Ordnance Survey, 2013. MasterMap Integrated Transport Network Layer. Southampton, UK. $<$ http://www.ordnancesurvey.co.uk/business-and-government/products/itn-layer.html >. 
Parent, O., LeSage, J., 2010. A Spatial Dynamic Panel Model with Random Effects Applied to Commuting Times. Transportation Research Part B 44, 633-645.

Pendyala, R.M., Kostyniuk, L.P., Goulias, K.G., 1995. A repeated cross-sectional evaluation of car ownership. Transportation, 22(2), 165-184.

Pirotte, A., Madre, J-L., 2011. Car Traffic Elasticities: A Spatial Panel Data Analysis of French Regions. Journal of Transport Economics and Policy 45, 341-365.

Polydoropoulou, A., Kamargianni, M., Tsirimpa, A., 2013. Car Use Addiction vs. Ecological Consciousness: Which one Prevails on Mode Choice Behavior? In M.J. Roorda \& E.J. Miller (Eds.): Travel Behaviour Research: Current Foundations, Future Prospects. Lulu Publishers, Toronto, Canada

Seya, H., Yamagata, Y., Tsutsumi, M., 2013. Automatic selection of a spatial weight matrix in spatial econometrics: Application to a spatial hedonic approach. Regional Science and Urban Economics 43 (3), 429-444

Schäfer, A., Victor, D.G., 2000. The future mobility of the world population. Transportation Research Part A 34 (3), 171-205.

Sharmeen, F., Timmermans, H., 2014. Walking down the habitual lane: analyzing path dependence effects of mode choice for social trips. Journal of Transport Geography 39, 222227.

Sihvola, T., Jokinen, J.P.; Sulonen, R., 2012. User Needs for Urban Car Travel Can DemandResponsive Transport Break Dependence on the Car? Transportation Research Record 2277, 7581

Tao, J., Yu, J., 2012. The spatial time lag in panel data models. Economics Letters 117, 544-547 Sung-Eun, K., Niemeier, D., 2001. A Weighted Autoregressive Model to Improve Mobile Emissions Estimates for Locations with Spatial Dependence, Transportation Science 35 (4), 413424

Thanos, S., Bristow A. L., Wardman, M. R., 2015. Residential sorting and environmental externalities: the case of non-linearities and stigma in aviation noise values. Journal of Regional Science 55(3), 468-490

Thanos, S., Dubé, J., Legros, D., 2016. Putting Time into Space: The Temporal Coherence of Spatial Applications in the Housing market, Regional Science and Urban Economics 58, 78-88 
Tversky, A., Kahneman, D., 1991. Loss aversion in riskless choice: A reference-dependent model. The quarterly journal of economics 106(4), 1039-1061.

Vega, S. H., Elhorst, J. P., 2015. The SLX Model. Journal of Regional Science 55(3), 339-363.

Wadud, Z., 2014. The asymmetric effects of income and fuel price on air transport demand.

Transportation Research Part A 65, 92-102.

Wolffram, R., 1971. Positivistic measures of aggregate supply elasticities: some new approaches - some critical notes. American Journal of Agricultural Economics 53 (2), 356-359.

Yu, J., De Jong, R., Lee, L-F., 2008. Quasi-maximum likelihood estimators for spatial dynamic panel data with fixed effects when both $\mathrm{n}$ and $\mathrm{t}$ are large. Journal of Econometrics 146,118-134. 